\title{
APONTAMENTOS SOBRE O DEVIDO PROCESSO CONSTITUCIONAL NO PROCESSO PENAL BRASILEIRO E A VIOLAÇÃO DE DIREITOS FUNDAMENTAIS DA POPULAÇÃO NEGRA
}

\section{NOTES ON THE CONSTITUTIONAL DUE PROCESS IN THE BRAZILIAN CRIMINAL PROCESS AND THE VIOLATION OF FUNDAMENTAL RIGHTS OF THE BLACK POPULATION}

\author{
Adilson Junio Freitas Costa* \\ Wendell Ferreira dos Santos ${ }^{* * *}$
}

\begin{abstract}
Resumo
Este artigo, instigado pela gravidade e repercussão do tema racial atualmente, tem por intuito realizar uma análise crítica da atual conjuntura social brasileira ao problematizar as execuções de pessoas negras pelo Estado e o tratamento desigual entre pessoas negras e brancas na aplicação da jurisdição penal a partir de uma ótica do Devido Processo Constitucional como uma garantia do Estado Democrático de Direito. Para isso, inicialmente é realizado um ensaio histórico sobre o Devido Processo Constitucional a partir do surgimento do Devido Processo Legal com Magna Carta em 1215. Mediante isso, é desenvolvido um raciocínio que acompanha as lutas e revoltas que aprimoraram aquele principio supracitado até sua promulgação na Constituição de 1988 com o advento do Estado Democrático de Direito. Após as considerações históricas estabelecidas, o texto apresenta uma análise crítica sobre as atuais e sistemáticas violações de Direitos Fundamentais que as pessoas negras são submetidas nas ações processuais penais do Estado. Posto este arranjo, é apresentado uma última análise, que disserta sobre a compatibilidade dos fatos problematizados acima com o princípio do Devido Processo Constitucional sob a ótica do Estado Democrático de Direito. Este estudo trata-se de uma investigação bibliográfica e vale se de dados quantitativos e qualitativos. Nas considerações finais é possível observar que o elemento primordial para o desmonte de uma estrutura que prejudica o acesso de negros aos direitos primeiros é a efetiva observância e aplicação dos princípios resguardados pela Constituição Brasileira de 1988 por parte dos integrantes do âmbito processual e agentes da lei.
\end{abstract}

Palavras-Chave: Devido Processo Constitucional. Direitos Fundamentais. Estado Democrático de Direito. Processo Penal.

Artigo submetido em 20 de julho de 2020 e aprovado em 19 de agosto de 2020.

*Graduando do curso de Direito pela PUC Minas. Email: adilsonjunio98@gmail.com.

** Graduando do curso de Direito pela PUC Minas. Email: wendellferreirads@ gmail.com. 


\begin{abstract}
This paper, instigated by the current repercussion of the theme, aims to realize a critical analyze about the current social circumstancesin Brazil problematizing the Black people murder's and fundamental rights violation by the State from a due process of law's optic as a constitutional right in the Democratic State Ruled by Law. To do this, at first is introduced a historical panorama from the due process of law starting in the Magna Cartha in 1215. From this, is developed a reasoning that follows the historical facts that refine this principle until it was recepted in the 1988's Brazilian Constitution. After this, is done a critical analyze about the current fundamental rights violations that Black people are subjected to in the the criminal procedure and also in his previous phases. To end it,will be presented a last analyze, that aims to check the matching of the narrated facts with the due process of Law. To end it, is presented a last alalyze that aims to check the matching of the narrated facts with the due process of law by the Democratic State Ruled by Law's optic. This research was done by qualitative and quantitative datas. In the final considerations is possible to conclude that the main element to disassemble a system that harm black people access to fundamental rights is the effective observation and application of the principles recognized in the 1988's Constitution by the procedure integrants and law agents.
\end{abstract}

Keywords: Due Process of Law. Fundamental Rights. Democratic State Ruled by Law. Criminal proceedings.

\title{
INTRODUÇÃO
}

O Direito Brasileiro contemporâneo é produto de uma construção histórica que do Jusnaturalismo ao Pós-Positivismo foi composto por movimentos sociais, lutas, revoltas, diferentes escolas de pensamento, normas e outras instituto que historicamente se aglutinaram construindo um sistema que enseja a organização e preservação dos indivíduos e da sociedade. Todavia, hodiernamente mesmo após séculos de aperfeiçoamento no fio histórico da humanidade, corriqueiramente direitos e garantias ainda são negados aos indivíduos. Em relação a esse problema, são inúmeras as violações de direitos individuais que poderiam ser citadas, contudo esse artigo irá ater-se em específico a um recorte racial da sociedade, tendo por pressuposto compreender as consequências do racismo no Estado Democrático de Direito brasileiro, que por sua vez figura como garantidor de preceitos de igualdade, entretanto é atravessado por uma estrutura social racista que negligencia e fere direitos da população negra.

Partindo desse pressuposto, é mister que sejam discorridas na academia produções sobre essa temática supracitada. Como é possível observar nos objetivos deste artigo, que são 
tornar visíveis as sistemáticas violações de direitos fundamentais da população negra e a importância da efetiva implementação e observação da clausula constitucional do Devido Processo como meio preventivo de possíveis decisões do sistema jurídico e da atuação coercitiva do Estado que sejam parcialmente danosas à população negra e que funcionem como manutenção do racismo no Brasil.

Para tanto, a metodologia aplicada na construção deste artigo tem natureza descritiva e faz um paralelo entre os problemas sociais existentes no país e a aplicação do direito brasileiro. Todas as fontes de pesquisa que forneceram materiais para complementação deste trabalho estão descritas no tópico "Referências" e são um misto de fontes primarias e secundarias (Livros, reportagens, aulas, textos). Toda bibliografia adotada na construção do trabalho tem o intuito de auxiliar o desenvolvimento de um raciocínio linear historicamente, com conceitos bem esclarecidos e números comprometidos com a realidade.

Em um primeiro plano, o artigo amplia a visão sobre o Devido Processo Constitucional a partir de uma perspectiva histórica e elucida os movimentos sociais que culminaram no estabelecimento do Devido Processo como um principio constitucional no Brasil a partir da Constituição de 1988.

Em um segundo momento, será destacado o papel desempenhado pelo Direito Penal na sociedade e as violações de direitos fundamentais da população negra no Brasil a partir de apontamentos que denunciam a desproporcionalidade e o exagero do punitivismo estatal em relação a pessoas negras.

Em um momento final, a abordagem se inclinará para uma análise sobre as violações de direitos fundamentais supracitadas diante de uma ótica do Devido Processo Constitucional como um princípio fundamental ao Estado Democrático de Direito.

\section{O DEVIDO PROCESSO CONSTITUCIONAL EM UMA PERSPECTIVA HISTÓRICA}

O Devido Processo Constitucional é um principio que surgiu após o fenômeno da Constitucionalização do Direito. A sua raiz histórica é o Devido Processo Legal, esse por sua vez, é um princípio regente nos Estados Democráticos do qual se emanam outros como: Isonomia, legalidade, ampla defesa, contraditório, publicidade, paridade de armas, proporcionalidade e outros. Sua função é proporcionar um julgamento verdadeiramente justo. 
Posto isto, é necessário de antemão se esclarecer o que é um principio dentro do Direito. Um principio é genericamente definido como uma meta a ser perseguida pelo Estado, que irradia valores no ordenamento positivo jurídico, orienta, produz harmonia e em muitas ocasiões suplanta a norma escrita. Guilherme de Souza Nucci firma que "o princípio jurídico significa um postulado que se irradia por todo o sistema de normas, fornecendo um padrão de interpretação, integração, conhecimento e aplicação do direito positivo, estabelecendo uma meta maior a seguir." (NUCCI, 2020, p.4)

Para explicar de que forma surgiu o Devido Processo é necessário se dedicar a entender cronologicamente os fatos históricos que culminaram na formação desse principio. Isso porque o Devido Processo é egresso de uma longa construção histórica, que mais precisamente inicia-se a partir da Magna Carta de 1215. O documento em questão é o produto da revolta dos Barões Ingleses em 15 de junho de 1215 contra os poder absoluto da Monarquia da Inglaterra, representada na figura do Rei João Sem Terra. As consecutivas derrotas políticas sofridas pelo monarca, a escassez de diplomacia e dialogo com a igreja, os atos despóticos protagonizados por esse, inflamaram a insatisfação da aristocracia e do Clero ingleses. Isso, consequentemente resultou na tomada de Londres pelos Barões, que forçaram o Rei João Sem Terra, em um momento de fragilidade e impopularidade, a assinar a "Magna Charta Libertatum”.

Esse documento consistiu na limitação dos poderes do Rei, que até então eram tidos como absolutos. A partir desse precedente, várias outras discussões foram desenroladas ao decorrer da história, como por exemplo, a afirmação da supremacia individual, o reconhecimento e a garantia dos Direitos Fundamentais por parte do Estado e a racionalização do poder. Para entender a dimensão da importância desse documento para a origem do Devido Processo, é cabível citar neste texto uma de suas 63 cláusulas:

Artigo 39. Nenhum homem livre será capturado ou aprisionado, ou desapropriado dos seus bens, ou declarado fora da lei, ou exilado, ou de algum modo lesado, nem nós iremos contra ele, nem enviaremos ninguém contra ele, excepto pelo julgamento legítimo dos seus pares ou pela lei do país. ${ }^{1}$ (INGLATERRA, 1215).

\footnotetext{
${ }^{1}$ A "Magna Charta Libertatum" de 1215 em seu texto original foi redigida em Latim. Texto original da clausula 39: "Nullusliber homo capiatur, velimprisonetur, autdisseisiatur, aututlagetur, autexuletur, autaliquo modo destruatur, necsupereumibimus, necsupereummittemus, nisi per legale judicium pariumsuorumvel per legem terre”.
} 
Malgrado, durante o século XVII, com a revolução Gloriosa em 1688, e os conflitos entre a Coroa e o Parlamento se acirrando, a Carta Magna foi revista, de modo que a majestade Guilherme de Orange cedeu uma série de prerrogativas aos parlamentares. Esse postulado foi denominado "Bill of Rights" (Lista de Direitos). Dessa forma, a monarquia constitucional inglesa foi sendo consolidada.

Indubitavelmente, a "Magna Charta Libertatum" foi o ponto axial para os movimentos jurídicos que se desenrolaram a partir de 1215 até a concretização da Monarquia Constitucional na Inglaterra. Posterior a isso e tendo a própria como um de seus fundamentos, se desencadeou o movimento de constitucionalismo na modernidade, já no século XVIII, concomitantemente aos ideais Jusnaturalistas, o que viria a culminar no recente Estado de Direito da Pós Modernidade. Dalmo de Abreu Dallari elucida quê:

"... no século XVIII, conjugam-se vários fatores que iriam determinar o
aparecimento das Constituições e infundir-lhes as características fundamentais. Sob
influência do jusnaturalismo, amplamente difundido pela obra dos contratualistas,
afirma-se a superioridade do indivíduo, dotado de direitos naturais inalienáveis que
deveriam receber a proteção do Estado. A par disso, desenvolve-se a luta contra o
absolutismo dos monarcas, ganhando grande força os movimentos que
preconizavam a limitação dos poderes dos governantes Por último, ocorre ainda à
influência considerável do Iluminismo, que levaria ao extremo a crença na Razão,
refletindo-se nas relações políticas através da exigência de uma racionalização do
poder". (DALLARI, Dalmo de Abreu,1976, p.26)

Posteriormente, no final século XVIII, período chamado pelo historiador Eric Hobsbawm de Era das Revoluções, acontecem às Revoluções Burguesas, também chamadas no Direito Constitucional de Revoluções Liberais, que deram inicio a um novo paradigma de organização do Estado. Especificamente nos Estados Unidos da América, em 1787, surge um novo modelo de Constituição, que diferentemente do modelo inglês, foi elaborado de forma dogmática. É necessário ressaltar que essa ampliava ainda mais as garantias individuais e é dotada de mais rigidez pelo fato de ser escrita e mais dificilmente modificada.

Já no século XX, após esse longo processo histórico o Devido Processo Legal recebe mais um adendo. Ao findar da Segunda Guerra Mundial e depois das experiências que denunciaram ao mundo os efeitos cataclísmicos que podem surgir a partir do abuso do poder estatal mostrado na experiência totalitarista e nazista do III Reich percebeu-se que eram necessários mecanismos mais avançados de controle do Estado e de garantia dos direitos individuais da humanidade. A partir de então, o Devido Processo não se restringe apenas ao meio formal, mas também passa a vigorar no controle do conteúdo das decisões, entendendo 
que a comparticipação dos agentes integrantes da estrutura processual é fundamental para garantir que os princípios fundamentais não sejam suprimidos por regras editadas em desconformidade com a Constituição. Haja vista que no período da Segunda Guerra os julgamentos na Alemanha Nazista eram realizados dentro dos pressupostos processuais exigidos a época, mas tinham decisões que notoriamente representavam sucessivos e graves ataques a princípios fundamentais ${ }^{2}$. Posto isto, é notório que para a realista aplicação deste principio é necessário não apenas a sua instauração na letra da lei (âmbito formalista), mas a sua observância na edição de leis posteriores e o controle substancial das decisões (âmbito material).

Hodiernamente, o principio ao qual este artigo versa, tem força constitucional resguardada na Constituição Brasileira Cidadã de 1988, fato que representa um marco para os direitos civis e fundamentais no Brasil. Na letra desta lei esta assim:

\footnotetext{
Art. $5^{\circ}$ Todos são iguais perante a lei, sem distinção de qualquer natureza, garantindo-se aos brasileiros e aos estrangeiros residentes no País a inviolabilidade do direito à vida, à liberdade, à igualdade, à segurança e à propriedade, nos termos seguintes:

LIV - ninguém será privado da liberdade ou de seus bens sem o devido processo legal;
}

É necessário que se desenvolva todo esse fio de raciocínio histórico realizado acima de modo que se circunscreva as lutas e movimentos que buscaram a concretização de direitos dos indivíduos e limites dos poderes Estatais para entendermos de forma mais adequada a importância da efetiva implementação do principio "Devido Processo Legal”.

Todavia, apesar de reconhecida a sua importância, o intuito deste artigo é versar sobre a eficácia deste principio para os indivíduos na contemporaneidade. Apesar de séculos de lutas e da promulgação deste pressuposto na Constituição Cidadã, como Devido Processo Constitucional, a indagação a ser feita é se é possível afirmar que essa garantia alcança a todos isonomicamente sem nenhuma distinção de raça.

\footnotetext{
${ }^{2}$ A Enciclopédia do Holocausto contida no site do Museu Memorial do Holocausto dos Estados Unidos, o "United StatesHolocaust Memorial Museum" informa que as Leis de Nuremberg são: "Duas leis distintas, aprovadas pela Alemanha nazista em setembro de 1935, são conhecidas coletivamente como "Leis de Nuremberg": (a) a Lei de Cidadania do Reich e (b) a Lei de Proteção do Sangue e da Honra Alemã. Estas leis incorporavam muitas das teorias raciais que embasavam a ideologia nazista. Elas constituíram a estrutura legal para a perseguição sistemática dos Judeus na Alemanha”.
} 


\title{
3 AS VIOLAÇÕES DE DIREITOS FUNDAMENTAIS DA POPULAÇÃO NEGRA PELO ESTADO
}

Como exposto no tópico anterior em que se discutiu sobre o Devido Processo Constitucional, este é um postulado que visa limitar o poder do Estado e garantir direitos aos indivíduos. Afirma-se que o Processo Penal, assim como qualquer outra forma de jurisdição exercida pelo Estado, é regido e regulado por uma série de princípios que visam garantir os direitos individuais. Isso porque o Direito Penal deve ter intervenção mínima, afinal estamos lidando com o cerceamento de direitos de indivíduos como forma de sanção, inclusive tratando da restrição da liberdade ambulatória. A Liberdade é um princípio consagrado na Constituição Brasileira e citado em suas diferentes formas ao longo de seu texto como, por exemplo, a liberdade de crença ou de expressão citadas em seu artigo quinto, onde há a previsão das garantias e direitos fundamentais dos indivíduos. O Estado Democrático de Direito no exercício de suas aptidões de punição na prática da jurisdição penal deve ser muito responsável em suas ações, afinal o mesmo Estado em questão é o que promulga a conjugação das três gerações de Direitos Fundamentais emanadas pela Revolução Francesa, a liberdade, igualdade e fraternidade. Em razão disso, há o entendimento que:

\begin{abstract}
No processo penal, existe um natural desequilíbrio na relação processual, pois o Estado, além de exercer o monopólio da atividade jurisdicional, via de regra, desempenha também a função acusatória, atuando como órgão processante (excepcionalmente a acusação será promovida pela vítima nas chamadas ações penais de iniciativa privada). Por isso, a atividade estatal deve ser controlada para que se alcance uma paridade, um equilíbrio na relação processual. Os princípios constitucionais revelam o modelo de Estado - social e democrático de direito escolhido pelos cidadãos que o compõe e servem como mecanismos de proteção da dignidade humana. A própria natureza do direito evidencia uma gênese valorativa, porquanto o ápice do conceito repousa sobre a justiça. Por consequência, ao se falar em sistema jurídico, obrigatoriamente, se fala em sistema valorativo. É tarefa do jurista pensar todas as consequências até o fim, transpor para casos comparáveis os valores legislados, solucionando contradições com outros valores existentes ou que venham a existir. E os princípios, assim considerados em relação ao ordenamento, podem ser identificados como a leitura dos valores, naturais ou positivos, hierarquizados conforme o interesse comum em determinado local e determinada época. São os chamados princípios gerais que dão unidade ao ordenamento. Os princípios, como nos explica Canaris, explicitam a valoração do direito, são como uma transcrição dos valores, em grau maior de concretude. (BRITO, BARRIONUEVO, FERREIRA, 2010, p.12)
\end{abstract}

A existência de um Direito Penal de intervenção mínima e de um processo penal garantista é uma conquista do Estado Democrático de Direito. As ações do Estado devem ser as menos lesivas possíveis aos direitos individuais e atender a critérios do princípio da 
proporcionalidade, que exige do poder estatal a escolha de meios adequados, eficazes e proporcionais.

Contudo, a desigualdade social tão evidente na sociedade também se reflete na aplicação do Direito. Ainda que os direitos fundamentais existam de forma declaratória, a realidade é outra para muitas pessoas que têm seus direitos violados no Processo Penal. Norberto Bobbio firmava a diferenciação da Igualdade em quatro formas, sendo do interesse desse artigo as definições de igualdade formal e igualdade substancial, chamadas pelo autor de igualdade perante a lei e igualdade de fato. A definição genérica que Bobbio atribuiu para os conceitos em "Igualdade e Liberdade" são as citadas no trecho a seguir, ainda que pecando pelo reducionismo da discussão proposta pelo autor na obra inteira:

Dos princípios da igualdade perante a lei e da igualdade de oportunidades, distingue-se a exigência ou o ideal da igualdade real ou substancial, ou, como se lê na Constituição italiana, de fato. $\mathrm{O}$ que se entende, genericamente, por igualdade de fato é bastante claro: entende-se a igualdade com relação aos bens materiais, ou igualdade econômica, que é assim diferenciada da igualdade formal ou jurídica e da igualdade de oportunidades ou social. (BOBBIO, 1997, p. 32)

Essa diferenciação atribuída por Bobbio é importante para esse artigo porque se observa o fato de ainda que formalmente, ou seja, de forma declaratória, a legislação penal preveja direitos para todos os indivíduos, a realidade é que as pessoas exercem esses direitos de forma muito desigual na Justiça. A disparidade em relação ao tratamento do Estado na aplicação do Direito Penal é observada a partir de diversos recortes teóricos e sociais possíveis, contudo esse artigo se atém ao ponto de como questões raciais atravessam o Direito Penal e influem na jurisdição do Estado, o que implica em violações de direitos fundamentais das pessoas negras.

As violações aos direitos e garantias dos indivíduos se iniciam ainda na fase préprocessual, onde há a investigação criminal realizada pela Polícia Civil e Federal, instituições do Estado. Faz-se ainda mais necessário citar também os agentes públicos responsáveis pela preservação da ordem pública e autorizados, portanto, a realizar investigações preventivas, os policiais militares. São inúmeras as denúncias a respeito de más condutas de policiais militares e outros agentes da segurança pública no exercício de suas atividades. Logo, é impossível falar sobre arbitrariedades do Estado contra a população negra sem citar a gravidade dos fatos que ocorrem no país, quando violações aos direitos fundamentais 
previstos em nossa Constituição são corriqueiras para essas pessoas devido às ilegais atuações desses agentes.

Esse assunto se coloca em evidência de forma ainda mais acentuada quando a morte de cidadãos negros acontece em decorrência de operações policiais e grandes tensões sociais são geradas a partir disso. Em 2020, no Brasil, o assassinato de João Pedro, um adolescente de 14 anos, no Rio de Janeiro, em uma ação policial, gerou enorme comoção social devido á conduta intolerável dos agentes públicos. Isso aconteceu quase ao mesmo tempo em que ondas de protesto contra o racismo aconteceram em todo o mundo devido ao assassinato de George Floyd, cidadão americano, negro, pelas mãos da polícia em Minnesota nos Estados Unidos. O caso de João Pedro não foi isolado, mas mais um na extensa lista de crianças negras condenadas a morte, ainda que indiretamente e por um julgamento irregular levando em consideração o fato destes não terem competência para isso, o que na mais crítica interpretação pode visualizar tal fato como um Tribunal de Exceção, por agentes do Estado em um país que atribui à maioridade penal apenas aos 18 anos e veda Constitucionalmente a possibilidade de pena de morte.

Ao discutir esse tema é possível observar que ainda está se discutindo a respeito da efetivação de Direitos de Primeira Geração, Direitos dos indivíduos frente ao Estado. Esses Direitos ainda não serem efetivos para a população negra mostra como o fator racial é um componente que ainda define a capacidade dos indivíduos de exercerem seus direitos de forma plena.

Já são muito graves os apontamentos feitos acima acerca das condutas dos agentes públicos na fase pré-processual. Contudo, a disparidade racial é também observada nas fases posteriores a citada. Dados informados no ano de 2017 pelo Depen (Departamento Penitenciário Nacional), por meio do Infopen (Levantamento Nacional de Informações Penitenciárias), indicam que atualmente, os negros são maioria no sistema prisional brasileiro, contabilizando $63,5 \%$ do total de pessoas privadas de liberdade no país. Além disso, ainda constata-se que 33\% dos presos, em geral, sequer tiveram condenação segundo a mesma pesquisa, ou seja, são presos provisórios.

Os dados ainda indicam que os crimes de Roubo, Furto e Tráfico de Drogas são os crimes que mais foram cometidos pelos detentos. Esses fatos constituem um paradoxo, por exemplo, com o fato de estudos indicarem de forma preliminar, cabendo aqui mais pesquisas 
que confirmem essa tese, que as pessoas brancas são as que mais cometem tais crimes, entretanto as pessoas negras ainda são as mais punidas ${ }^{3}$.

O Processo Penal deve ser Constitucional, esse é um efeito da Constitucionalização do Direito. O Devido Processo Constitucional deve ser seguido a fim de garantir proteção aos indivíduos e isso é impossível quando sequer a Igualdade Formal, a Igualdade perante a lei, é concretizada para a maior parte da população. Em razão disso, pode se constatar que os fatos descritos se enquadram como grandes afrontas ao princípio em questão.

\section{O DEVIDO PROCESSO CONSTITUCIONAL E A EXECUÇÃO DE PESSOAS NEGRAS SOB A ÓTICA DO ESTADO DEMOCRÁTICO DE DIREITO}

A partir do que foi observado nos tópicos precedentes é possível afirma que um Estado Democrático de Direito, como a República Federativa do Brasil se proclama em sua Constituição Federal, deve ter limites no exercício de sua aptidão para punir aoconstar com princípios que regulem a sua atuação. Entretanto, esses princípios não são observados quando o Estado age de forma ilegal contra os cidadãos.

\footnotetext{
Portanto, o Estado somente poderá ser democrático se e quando o povo exercer efetivamente o poder por meio de seus representantes, ou, em algumas circunstâncias, diretamente. Além disso, é, efetivamente sobremais disso, mister que direitos fundamentais constem das cartas políticas e sejam cabalmente respeitados. Em conseqüência, o Estado de Direito é estado de legitimidade. (FIGUEIREDO, 1997, p.8)
}

O Devido Processo Constitucional é um dos instrumentos consagrados no Estado Democrático de Direito e consiste em dois pontos muito importantes que são feridos pela jurisdição do Estado, quando esta não observa os princípios que lhe regem, sendo eles:

i) A Constitucionalização do Direito: A transformação do Direito em um ordenamento que está submetido aos efeitos que a Constituição erradia. "A idéia de constitucionalização do Direito aqui explorada está associada a um efeito expansivo das normas constitucionais, cujo conteúdo material e axiológico se

\footnotetext{
${ }^{3}$ Reportagem do Site "Ponte" com o título "Por que é racismo dizer que negros são mais criminosos que brancos" traz estudos e dados que indicam que as pessoas brancas cometem mais crimes que pessoas negras, entretanto são menos punidas por isso. Dentre esses dados, figuramuma tese de mestrado em Ciência Política de 2006 que apontou o fato 59,5\% dos réus por furto em São Paulo eram brancos, enquanto 40,1\%, negros. Quanto aos roubos, $51,4 \%$ tinham réus brancos frente a 48,3\% de negros; estudo do professor de sociologia na USP (Universidade de São Paulo) Sérgio Adorno que identificou o fato de 59,4\% dos brancos recebiam condenação, enquanto o mesmo ocorria com 68,8\% dos negros julgados em São Paulo e, por último, uma reportagem da Agência Pública responsável por fazer um levantamento de 4 mil sentenças de tráfico em 2017 que o apontou o fato de negros serem mais condenados com uma menor quantidade de drogas do que os brancos.
} 
irradia, com força normativa, por todo o sistema jurídico.“ (BARROSO, 2005, p.12).

ii) O Devido Processo Legal: Este, por sua vez, é um princípio basilar dos Estados Democráticos. Os efeitos da Constitucionalização do Direito lhe tornaram então um Processo Constitucional.

Um Estado Democrático de Direito que tem o uso legítimo da força perde a sua legitimidade quando age em sentido contrário aos princípios que the fundamentam. As inúmeras violações de Direitos Fundamentais da população negra no Processo Penal Brasileiro discorridas nesse artigo configuram em uma grave afronta não somente aos direitos individuais dessas populações, mas também aos próprios princípios inerentes a formulação do Estado de Direito, o que coloca em questionamento sua legitimidade e efetividade.

A legitimidade de um Governo que infringe os direitos de seus cidadãos é tema recorrente para a literatura sobre as democracias ocidentais e o liberalismo político. Um dos grandes pensadores, cujo se atribuí muita influência na formação da democracia liberal, o contratualista John Locke, já trazia em sua obra "O Segundo Tratado do Governo Civil" o Direito a Rebelião, que surgia para os indivíduos quando o Estado deixasse de agir para os fins que os cidadãos lhe conferiram o poder, que era resguardar seus direitos naturais de liberdade e propriedade. Apesar de na Democracia contemporânea inexistir o conceito de Direito Natural, a legitimidade do Estado democrático continua a depender de uma complexidade de princípios e garantias individuais que devem ser cumpridas. Portanto, qualquer literatura acadêmica minimamente coerente não pode observar normalidade nas inúmeras violações de Direitos Fundamentais da população negra, no âmbito deste artigo o direito ao Devido Processo Constitucional, praticadas pelo Estado.

\section{CONSIDERAÇÕES FINAIS}

O ideal desse artigo foi realizar apontamentos acerca de interferências raciais na implementação de garantias básicas e fundamentais para a população negra no Brasil, garantias àquelas que são demarcadas na Constituição Federal de 1988, em especial o Devido Processo Constitucional, e de acordo com o que está nela postulado deveriam ser resguardadas a todo e qualquer individuo indiscriminadamente.

Contudo ao decorrer da elaboração deste artigo constatou-se que a hipóteses de infração dos direitos fundamentais dessa população a partir da não observação desses 
princípios em questão pela jurisdição do Estado. Mesmo diante de um série de Direitos já positivados e de um princípio constitucional regente que se irradia pelo ordenamento jurídico e se estende a todas as formas de exercício do poder, sejam essas formas publicas ou privadas, ainda sim rotineiramente existem violações de varias naturezas: execuções, encarceramentos em massa e judiciais decisões desproporcionais quando comparadas com pessoas brancas.

Posto estas alegações, entende-se que a única alternativa para extinção de um sistema jurídico que anui e ainda mais fomenta o racismo é a verdadeira observação dos princípios regentes em todas as decisões do âmbito penal e o controle do exercício de poder em todas as instancias. Ademais é de suma importância que todos os agentes que integram o processo penal de forma comparticipada estimulem uma decisão que seja constitucionalmente aceita de modo que vidas negras e seus demais direitos individuais mais básicos a condição humana, como sua liberdade e o direito a um julgamento justo, sejam preservados.

\section{REFERÊNCIAS}

As Leis de Nuremberg. United States Holocaust Momorial Museum

https://encyclopedia.ushmm.org/content/pt-br/article/nuremberglaws\#: : text=Duas\%20leis\%20distintas\%2C\%20aprovadas \%20pela,que \%20embasavam\%20 a\%20ideologia\%20nazista. Acesso em 16 de Jul 2020.

BARROSO, Luis Roberto. Neoconstitucionalismo e constitucionalização do Direito: O triunfo tardio do direito constitucional no Brasil. Revista de Direito Administrativo, Rio de Janeiro, v. 240, p. 1-42, abr. 2005. ISSN 2238-5177. Disponível em:

http://bibliotecadigital.fgv.br/ojs/index.php/rda/article/view/43618/44695. Acesso em: $14 \mathrm{Jul}$. 2020. doi:http://dx.doi.org/10.12660/rda.v240.2005.43618.

BOBBIO, Norberto. Igualdade e liberdade; tradução de Carlos Nelson Coutinho. $2^{\mathrm{a}}$ ed. -Rio de Janeiro: Ediouro, 1997.

BRASIL.[Constituição (1988)]. Constituição da Republica Federativa do Brasil de 1988. Brasília, DF: Presidência da Republica, [2020]. Disponível em:

http://www.planalto.gov.br/ccivil_03/constituicao/constituicao.htm. Acesso em: 01 de julho. 2020.

BRASIL. DEPEN. Departamento Penitenciário Nacional. Disponível em: http://depen.gov.br/DEPEN/depen/sisdepen/infopen/relatorios-sinteticos/infopen-jun-2017rev-12072019-0721.pdf. Acesso em: 20 de Jun 2020.

BRITO, Alexis Couto de; FABRETTI, Humberto Barrionuevo; LIMA, Marco Antônio Ferreira. Processo Penal Brasileiro. Editora Atlas, $4^{\circ}$ edição: São Paulo. 2019. 
DALLARI, Dalmo de Abreu. Elementos de Teoria Geral do Estado. 3. Ed., São Paulo: Saraiva,1976.

FIGUEIREDO, Lúcia Valle. Estado de Direito e devido processo legal. Revista de Direito Administrativo, Rio de Janeiro, v. 209, p. 7-18, jul. 1997. ISSN 2238-5177. Disponível em: http://bibliotecadigital.fgv.br/ojs/index.php/rda/article/view/47039/46023. Acesso em: 14 Jul. 2020. doi:http://dx.doi.org/10.12660/rda.v209.1997.47039.

LEITE, Gisele. Constitucionalismo e sua historia. Âmbito Jurídico, 2011. Disponível em: https://ambitojuridico.com.br/cadernos/direito-constitucional/constitucionalismo-e-suahistoria. Acesso em 10 de Jul. 2020.

LOURENCETTE, Lucas Tadeu. Magna Charta Libertatum. DireitoNet,2007. Disponível em: https://www.direitonet.com.br/artigos/exibir/6582/Magna-chartalibertatum\#: : :ext=A\%20Magna\%20Charta\%20Libertatum\%2C\%20assinada,acerca\%20das \%20prerrogativas\%20do\%20monarca. Acesso em 10 de Jul 2020.

NUCCI, Guilherme de Souza. Manual de processo penal. 1. ed. - São Paulo: Editora GEN Forense, 2020.

STABILE, Arthur. Por que é racismo dizer que negros são mais criminosos do que brancos. Ponte, 2020. Disponível em: https://ponte.org/por-que-e-racismo-dizer-que-negros-sao-maiscriminosos-do-que-brancos/. Acesso em: 20 de Jun 2020. 